Article

\title{
Regenerable Antibacterial Cotton Fabric by Plasma Treatment with Dimethylhydantoin: Antibacterial Activity against $S$. aureus
}

\author{
Chang-E. Zhou ${ }^{1}$, Chi-wai Kan ${ }^{1, *}$, Jukka Pekka Matinlinna ${ }^{2}$ and James Kit-hon Tsoi ${ }^{2}$ \\ 1 Institute of Textiles and Clothing, The Hong Kong Polytechnic University, Hung Hom, Kowloon, \\ Hong Kong, China; change_fly@163.com \\ 2 Dental Materials Science, Faculty of Dentistry, The University of Hong Kong, Pokfulam, Hong Kong, China; \\ jpmat@hku.hk (J.P.M.); jkhtsoi@hku.hk (J.K.-h.T.) \\ * Correspondence: tccwk@polyu.edu.hk; Tel.: +852-2766-6531; Fax: +852-2773-1432
}

Academic Editor: Mahbubul Hassan

Received: 28 October 2016; Accepted: 11 January 2017; Published: 18 January 2017

\begin{abstract}
This study examined the influence of variables in a finishing process for making cotton fabric with regenerable antibacterial properties against Staphylococcus aureus (S. aureus). 5,5-dimethylhydantoin (DMH) was coated onto cotton fabric by a pad-dry-plasma-cure method. Sodium hypochlorite was used for chlorinating the DMH coated fabric in order to introduce antibacterial properties. An orthogonal array testing strategy (OATS) was used in the finishing process for finding the optimum treatment conditions. After finishing, UV-Visible spectroscopy, Scanning Electron Microscopy (SEM), and Fourier Transform Infrared Spectroscopy (FTIR) were employed to characterise the properties of the treated cotton fabric, including the concentration of chlorine, morphological properties, and functional groups. The results show that cotton fabric coated with DMH followed by plasma treatment and chlorination can inhibit S. aureus and that the antibacterial property is regenerable.
\end{abstract}

Keywords: plasma; regenerable; antibacterial; cotton; DMH

\section{Introduction}

Antibacterial finishing is of enormous importance in the textile industry because fibres are susceptible to microorganisms, including bacteria and fungi, which are nourished by sweat, sebum, and food stains, as well as the fibres themselves [1-4]. These microorganisms can cause odor, staining, deterioration of textiles, and infection, allergies, and diseases. Cotton is a natural cellulosic fibre which has the ability to absorb and retain moisture and promote the growth of microorganisms $[5,6]$. Therefore, antibacterial finishing for cotton fabric is imperative. To achieve safety and health properties, antibacterial cotton fabric is grafted or coated with bactericides (e.g., chitosan, quaternary ammonium salts, chlorine and chloramines, etc.) [7-11], or loaded with heavy metal ions (silver, copper, zinc) [12-15]. However, it is found that the uptake and durability of these compounds are difficult to manage because they leach from the textiles easily [7]. These chemicals are always loaded onto cotton fabrics with the help of other chemicals, such as cross-linking agents, initiators, and catalysts, but the incompatibility of antibacterial agents with other chemicals and the toxicity of these antibacterial agents to humans and aquatic animals are also important weaknesses that need to be addressed [7]. In order to reduce chemical consumption, protect the environment, and improve the quality of textiles, researchers have worked hard to find innovative solutions. Plasma treatment is one of the methods used to improve textile manufacturing processes. Plasma technology has already been used by the textile industry for surface modification and for imparting permeability and 
biocompatibility [16-19]. Plasma is a medium composed of ions, free electrons, photons, neutral atoms, and molecules in ground and excited states [20]. These particles, generated from the dissociation of inert gases under electrical energy, gain their own energy from an imposed electric field and lose this energy when they collide with the material surface. During the surface collision, chemical bonds in the material surface are ruptured and free radical groups are created on the material surface. These particles are chemically active and can introduce new functional groups on the surface of the material which can be used as precursors for polymerisation; a reaction between the substrate and the monomer [20]. Plasma treatment applied in textile processes replaces application of some chemicals, thereby reducing the amount of chemicals used during production. This reduces the environmental effects of textile production. The main advantage of plasma treatment is that it just changes the surface properties without affecting the bulk properties of substrates [21,22].

Finishing of cotton fabric with chloramine (pad-dry-cure) with the aid of plasma treatment is proposed because of environmental concerns. The chloramine is changed from 5,5-dimethylhydantoin (DMH), a chemical with an amide structure, to an N-halamine structure by chlorination. The chlorine in chloramine can be regenerated through chlorination after consumption by bacteria (Figure 1). This finishing method makes antibacterial textiles regenerable. In the reaction, chlorine in the $\mathrm{N}$-halamine structure is not stable due to the inductive effect of the carbonyl $(\mathrm{C}=\mathrm{O})$ [23]. It can attach to bacteria easily to change the osmotic pressure of the bacteria and kill it. At that time, the chlorine in $\mathrm{N}$-halamine is substituted with a hydrogen ion. However, the chlorine in N-halamine can be obtained again by chlorination of sodium hypochlorite. Therefore, this finishing process improves the lifespan of the antibacterial properties of cotton fabric. In addition, the chemical structure of DMH is simple and the reagent itself is inexpensive and easily available. In our preliminary study [24], we found that plasma treatment can improve the pad-dry-cure process for introducing $\mathrm{DMH}$ to cotton fabric to achieve good antibacterial effects. The plasma process can be carried out at different stages of the pad-dry-cure process, i.e., plasma-pad-dry-cure (CPD); pad-plasma-dry-cure (CWPD), and pad-dry-plasma-cure (CDPD) [24], in order to make cotton fabric with antibacterial properties [24]. Experimental results reveal that CDPD treatment can provide the best antibacterial effect against $S$. aureus compared with CPD, CWPD, and even the "pad-dry-cure" process without plasma treatment $(C D)$. Further studies were conducted in order to optimize the treatment conditions for CD [25], CPD [26], and CWPD [27] but the optimum condition for the CDPD process has not been reported yet. Therefore, the optimum condition for the CDPD process is investigated in this study.
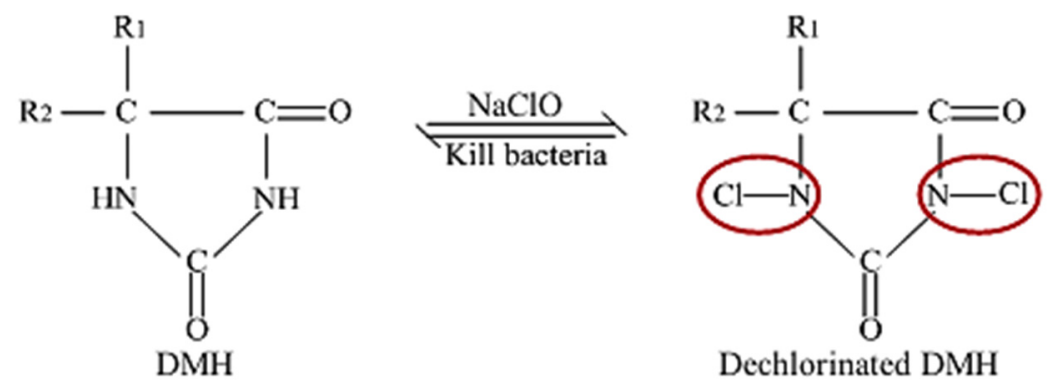

Figure 1. Reversible redox reaction of DMH (red circles show the N-halamine structure) [25].

\section{Experimental Methods}

\subsection{Fabric and Chemicals}

$100 \%$ woven cotton fabric, completely desized, scoured, and bleached, was used in this study (fabric weight $=260 \mathrm{~g} / \mathrm{m}^{2} ; 54$ threads $/ \mathrm{cm}$ in warp and 25 threads $/ \mathrm{cm}$ in weft). Non-ionic detergent, Diadavin EWN-T 200\% (Tanatex, Leverkusen, Germany) (2\%), was used for cleaning the fabric at pH 7 at $50{ }^{\circ} \mathrm{C}$ for $30 \mathrm{~min}$. After cleaning, the fabric was rinsed with deionised water to remove detergent, oil, and impurities and dried at $80^{\circ} \mathrm{C}$ for $20 \mathrm{~min}$ [23-27]. The cleaned fabric was then conditioned 
at $65 \% \pm 2 \%$ relative humidity and $20 \pm 2{ }^{\circ} \mathrm{C}$ for at least $24 \mathrm{~h}$ prior to further use. 5,5-Dimethyl hydantoin (DMH) $(97 \%)$, sodium hypochlorite ( $5 \%$ active chlorine content), potassium iodide, glacial acetic acid $(>99.8 \%)$, and starch indicator $\left(1 \%\right.$ in $\left.\mathrm{H}_{2} \mathrm{O}\right)$ were purchased from Sigma-Aldrich.

\subsection{Plasma Treatment}

Atmospheric pressure plasma (APP) treatment was conducted after drying during the conventional pad-dry-cure process. Plasma generator Atomflo-200 (Surfx Technology, Redondo Beach, CA, USA) was used for APP treatment of the cotton fabric. The plasma discharge was ignited by low radio frequency at $13.56 \mathrm{MHz}$. In the APP treatment system, the plasma jet was placed vertically above the fabric (Figure 2) [23-27]. As described in detail previously [23-27], helium (flow rate $=9.6 \mathrm{~L} / \mathrm{min}$ ) and nitrogen (flow rate $=0.15 \mathrm{~L} / \mathrm{min}$ ) were used as the carrier gas and reactive gas, respectively. The APP discharge power was $80 \mathrm{~W}$, the jet distance was $5 \mathrm{~mm}$, and the movement speed of the fabric was $0.2 \mathrm{~m} / \mathrm{s}$.

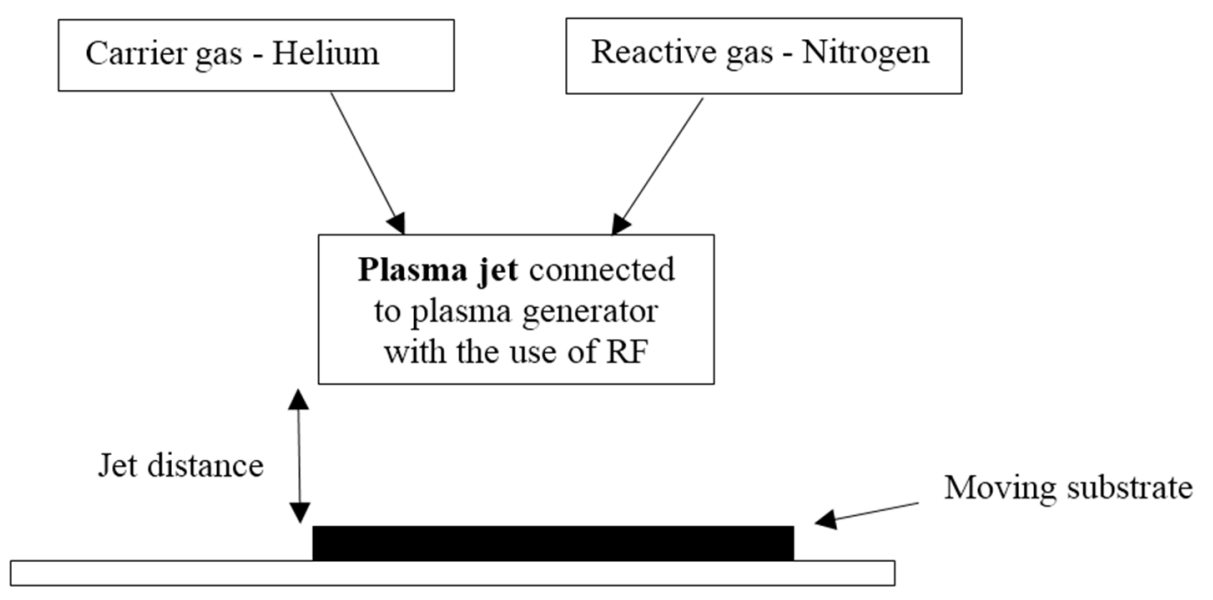

Figure 2. Schematic diagram of the Atmospheric pressure plasma (APP) treatment.

\subsection{Optimising the Treatment Condition for Coating DMH on Cotton Fabric}

For the coating of DMH, cotton fabric was first padded with DMH (with concentrations of $2 \%, 4 \%$, or $6 \%$ ) until a wet pick up of $80 \%$ was achieved. The DMH padded cotton fabric was then dried at $80{ }^{\circ} \mathrm{C}$ for $5 \mathrm{~min}$, similar to previous studies [24-27]. The dried fabric was then treated with plasma and cured at $120^{\circ} \mathrm{C}, 140{ }^{\circ} \mathrm{C}$, or $160^{\circ} \mathrm{C}$ for $5 \mathrm{~min}$ (i.e., pad-dry-plasma-cure). The fabric samples treated with the same coating process were subsequently chlorinated at room temperature with sodium hypochlorite solution with different active chlorine contents of $0.8 \%, 1.0 \%$, or $1.2 \%$, in order to transform some of the amino groups on the pad-dry-plasma-cure treated cotton fabric into N-halamines [24-27]. After chlorination with sodium hypochlorite, these fabrics were rinsed thoroughly with deionised water in order to ensure that no free chlorine remained in the chlorinated fabric. To test the free chlorine, the water after rinsing the chlorinated fabric was tested with $\mathrm{KI} /$ starch solution. If no blue color was observed in the rinsing water, this indicated that no free chlorine remained in the fabric [24-27]. After the chlorination process, the cotton fabrics were conditioned at $65 \% \pm 2 \%$ relative humidity and $20 \pm 2{ }^{\circ} \mathrm{C}$ for at least $24 \mathrm{~h}$ prior to use [26,27].

Orthogonal array testing strategy (OATS) analysis was used for determining the optimum treatment conditions [25-29]. Four variables which have been used previously [25-27] were adopted, i.e., the concentration of $\mathrm{DMH}$, curing temperature, concentration of the bleaching solution, and the duration of chlorination and their respective effects on antibacterial properties were investigated. Table 1 summarises the variables and levels used in the OATS analysis and Table 2 shows the experimental arrangements (nine test runs were conducted). 
Table 1. Variables and levels used in OATS [25-27].

\begin{tabular}{ccccc}
\hline & \multicolumn{3}{c}{ Variables } \\
\cline { 2 - 5 } Level & $\begin{array}{c}\text { Concentration } \\
\text { of DMH (\%) }\end{array}$ & $\begin{array}{c}\text { Curing } \\
\text { Temperature }\left({ }^{\circ} \mathbf{C}\right)\end{array}$ & $\begin{array}{c}\text { Concentration of } \\
\text { Bleaching Solution (\%) }\end{array}$ & $\begin{array}{c}\text { Time of } \\
\text { Chlorination (min) }\end{array}$ \\
\cline { 2 - 6 } & A & B & C & D \\
II & 2 & 120 & 0.8 & 20 \\
II & 4 & 140 & 1.0 & 60 \\
\hline
\end{tabular}

Table 2. Arrangement of experiment [25-27].

\begin{tabular}{|c|c|c|c|c|}
\hline \multirow[b]{2}{*}{ Test Run } & \multicolumn{4}{|c|}{ Variables } \\
\hline & $\begin{array}{l}\text { Concentration } \\
\text { of DMH (\%) }\end{array}$ & $\begin{array}{c}\text { Curing } \\
\text { Temperature }\left({ }^{\circ} \mathrm{C}\right)\end{array}$ & $\begin{array}{c}\text { Concentration of } \\
\text { Bleaching Solution (\%) }\end{array}$ & $\begin{array}{c}\text { Time of } \\
\text { Chlorination (min) }\end{array}$ \\
\hline & A & B & $\mathrm{C}$ & D \\
\hline 1 & $\mathrm{I}$ & I & I & I \\
\hline 2 & I & II & II & II \\
\hline 3 & I & III & III & III \\
\hline 4 & II & I & II & III \\
\hline 5 & II & II & III & I \\
\hline 6 & II & III & I & II \\
\hline 7 & III & I & II & II \\
\hline 8 & III & II & I & III \\
\hline 9 & III & III & II & I \\
\hline
\end{tabular}

\subsection{Antibacterial Property}

Antibacterial activity of the samples was tested referring to the AATCC Test Method 147-2011. S. aureus (ATCC 6538, purchased from Tin Hang Technology Ltd in Hong Kong) was used as the model bacteria [4,30-32]. The bacteria were inoculated in a blood agar plate purchased from Tin Hang Technology Ltd in Hong Kong and incubated at $37^{\circ} \mathrm{C}$ for $24 \mathrm{~h}$. A bacterial suspension was prepared in Brain-Heart Infusion (BHI) (Oxoid, purchased from Thermo Fisher Scientific HK Ltd., Hong Kong, China) broth by harvesting the cells from the blood agar plate and its optical density was measured with a UV-Vis spectrophotometer (DU 730, Beckman Coulter HK Ltd., Hong Kong, China) (wavelength at $660 \mathrm{~nm}$ ) to $0.5 \mathrm{McF}$ arland standard. Then, the suspension was diluted 100-fold. After that, the diluted suspension was inoculated on new sterile blood agar plates using the Autoplate 4000 microprocessor-controlled Spiral Platter (Advanced Instruments, Inc., Norwood, MA, USA), and untreated and freshly prepared treated samples $(20 \mathrm{~mm} \times 20 \mathrm{~mm})$ were placed on the seeded agar surfaces. After standing for 5-10 min, these plates were placed in the aerobic incubator and incubated at $37^{\circ} \mathrm{C}$ for $48 \mathrm{~h}$. Finally, clear zones were observed to evaluate the antibacterial activity of the samples. The antimicrobial activity of each sample was tested three times, and the mean value of the width of three clear zones was used to evaluate the antimicrobial activity of the fabric.

\subsection{Active Chlorine Content of Chlorinated DMH Coated in Cotton Fabric}

A colorimetric method was used for evaluating the active chlorine content of chlorinated DMH coated on cotton fabric, as described previously [24-27]. The available active chlorine content of the fabric was determined based on the absorbance measured by the Lambda 18 UV-Visible spectrophotometer (Perkin Elmer, Waltham, MA, USA) at wavelength $\left(\lambda_{\max }=427.60 \mathrm{~nm}\right)$. A calibration curve was prepared by measuring the absorbance of three standard sodium hypochlorite solutions. In the calibration curve, absorbance is plotted against concentration (the best fit equation of the calibration curve is $y=30.401 x-50.84 ; R^{2}=0.9918$ ). Based on the calibration curve, the concentration of active chlorine of the DMH coated fabric samples can be obtained [24-27].

\subsection{Regenerability}

The regenerability of chlorine in the cotton fabric was tested by washing using the AATCC Test Method 61-1A [25-27]. The antibacterial activity of samples before washing, after washing (termed as AW), 
and after re-chlorination was tested (termed as $\mathrm{AW}+\mathrm{CH}$ ). The conditions for re-chlorination were the same as the first chlorination process.

\subsubsection{Chemical Composition of DMH Coated Fabric}

Fourier transform infrared spectroscopy was used for evaluating the chemical properties of DMH coated fabrics. A Spectrum 100 with attenuated total reflection mode was used for obtaining the FTIR spectra. The spectra were obtained using 16 scans between 650 and $4000 \mathrm{~cm}^{-1}$ with a resolution of $4 \mathrm{~cm}^{-1}$. For obtaining better spectra with low noise, the second derivative of the spectra was obtained, for further analysis of the chemical composition of DMH coated fabric [25-27].

\subsubsection{Scanning Electron Microscopy (SEM)}

Surface morphology of the cotton fabric was evaluated by SEM (JEOL Model JSM-6490, JEOL USA, Inc., Peabody, MA, USA) with imaging up to $300,000 \times$ with a high resolution of $3 \mathrm{~nm}$. Samples $(5 \mathrm{~mm} \times 5 \mathrm{~mm})$ were pasted on a metal round table with conducting resin. They were then placed in the vacuum pump of the SEM. The surface images of fabrics were obtained by the SEM operated at an accelerating voltage of $20 \mathrm{kV}$ and magnification of the image was set at $4000 \times$ to $5000 \times$.

\subsubsection{Tearing Strength}

Tearing strength of untreated fabrics, fabrics coated with DMH (CD), and fabric coated with DMH with plasma treatment (CDPD) was measured in accordance with the American Society for Testing and Materials (ASTM) D1424-09 "Standard Test Method for Tearing Strength of Fabrics by Falling-Pendulum Type (Elmendorf) Apparatus" with an Elmatear Digital Tear Tester (James H. Heal \& Co. Ltd., Halifax, UK). Three samples per fabric type for both the warp (for tearing across the weft) and the weft (for tearing across the warp) direction were tested. The dimensions of the samples were about $(75 \pm 2) \mathrm{mm} \times(100 \pm 2) \mathrm{mm}$ based on the template in accordance with the requirements in ASTM D 1424-09 [33]. The results of the tearing strength were represented in newton (N).

\section{Results}

\subsection{Optimised Treatment Condition for Antibacterial Finishing}

In this study, the mean value of the width of four clear zones in a fabric (Figure 3) is used to evaluate the antibacterial activity of the fabric against $S$. aureus and is termed mean clear width. A wider clear width indicates the antibacterial activity is more pronounced. The mean clear width of the bacteria against $S$. aureus was obtained from the nine specimens generated by the OATS technique and the result of orthogonal analysis, where $T_{\mathrm{mn}}$ refers to the sum of the evaluation indexes of all levels $(n, n=\mathrm{I}$, II, III) in each factor $(m, m=\mathrm{A}, \mathrm{B}, \mathrm{C})$, such that TAI $=1.156+1.090+1.611=3.857$ is the sum of level I of factor A; TCII $=1.090+1.062+1.258=3.410$ is the sum of level II of factor C; and $K_{\mathrm{mn}}$ implies the mean value of $T_{\mathrm{mn}}$, such that $\mathrm{KAI}=\mathrm{TAI} / 3=3.857 / 3=1.286$ is the mean value of TAI; KCII $=\mathrm{TCII} / 3=3.410 / 3=1.137$ is the mean value of TCII, and all are shown in Table 3 . In addition, $T$ is the sum of the evaluation indexes, $w_{i}$, which is an evaluating indicator for antimicrobial activity of cotton fabrics evaluated by the AATCC Test Method 147-2011; and the range of factors in each column, $R=\operatorname{Max}\left(K_{j}\right)-\operatorname{Min}\left(K_{j}\right)$, indicates the function of the corresponding factor [34]. The larger value of $R$ corresponds to a greater impact of the level of the factor on the experimental index. Therefore, the impact of every factor on the final treatment effect can be distinguished clearly on the comprehensive condition that every factor changes. 


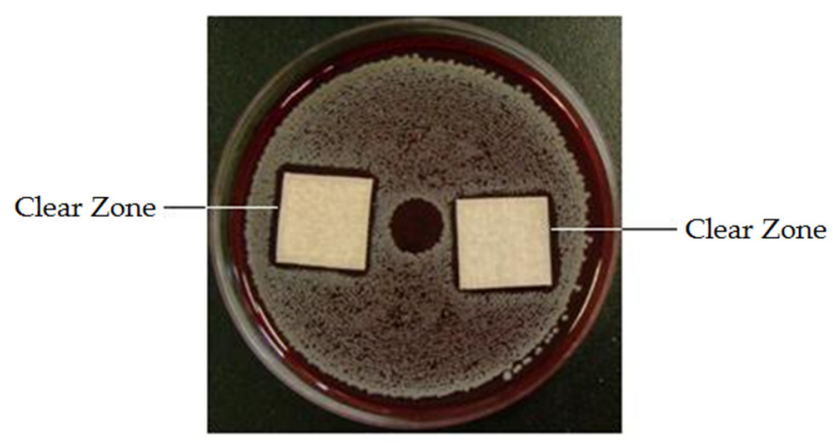

Figure 3. Example of the clear zone of the sample against bacteria [24].

Table 3. Orthogonal table for optimizing the antibacterial property of cotton fabric coated with DMH.

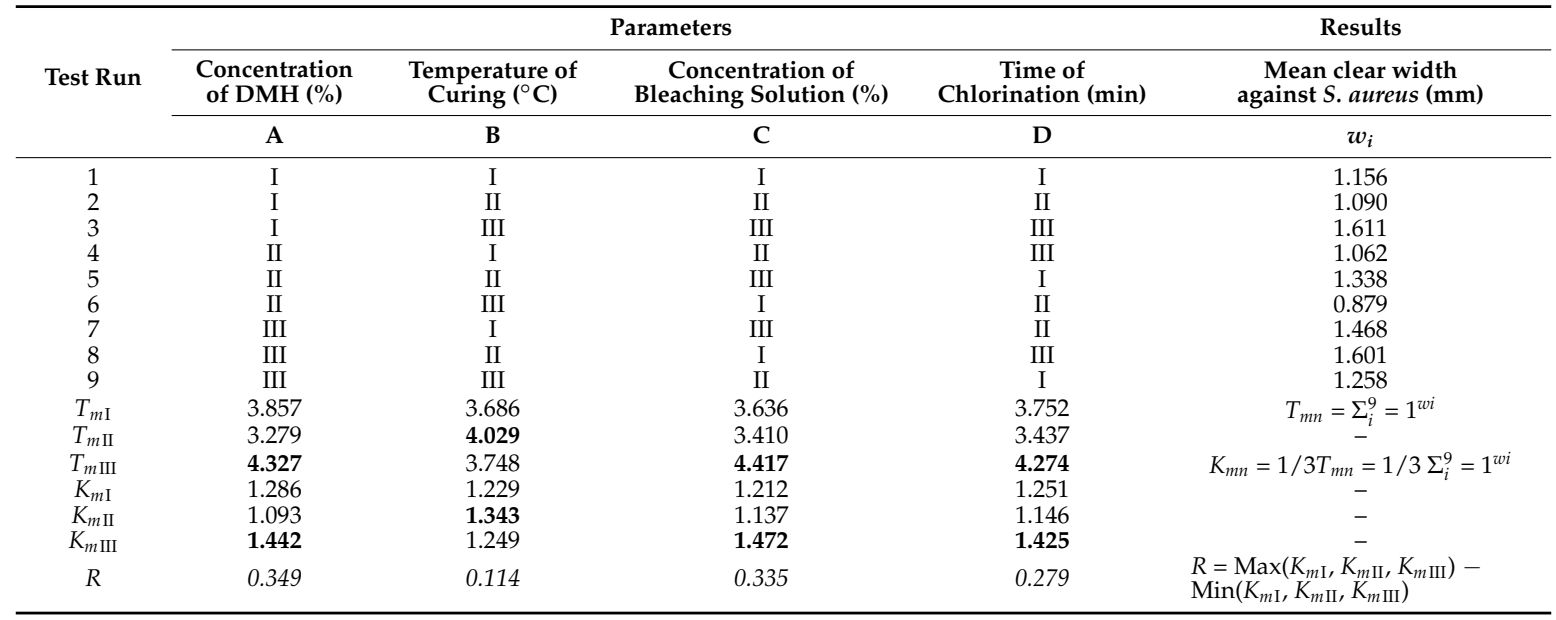

Figures in bold exhibit the highest value among all values of different variables used while italics show the level of importance of each variable.

Based on Table 3, all the four variables used, i.e., (i) concentration of DMH; (ii) curing temperature; (iii) concentration of bleaching solution; and (iv) time of chlorination, in the antibacterial finishing process can have different effects on antibacterial activity of cotton fabric coated with DMH in the CDPD process. The order of importance of these variables based on the OATS analysis is concentration of $\mathrm{DMH}>$ concentration of bleaching solution $>$ time of chlorination > curing temperature. According to the results of the OATS analysis, the optimum conditions for DMH coating on cotton fabric in the CDPD process are: (i) concentration of DMH is 6\%; (ii) curing temperature is $140{ }^{\circ} \mathrm{C}$; (iii) concentration of bleaching solution is $1.2 \%$; and (iv) time of chlorination is $60 \mathrm{~min}$. In order to verify these optimum conditions, cotton fabric was treated under the optimum conditions and it was found that the mean clear width was $1.798 \mathrm{~mm}$ and this width is the widest when compared with the nine specimens' results in Table 3. Therefore, the optimum conditions were determined and the cotton fabric was treated under these optimum conditions for further evaluation of regenerability, by FTIR-ATR and SEM.

The effect of process variables including (i) concentration of DMH; (ii) time for curing; (iii) concentration of bleaching solution; and (iii) time of chlorination on the antimicrobial results was investigated (Figure 4). The effect of the concentration of DMH on the antibacterial property is shown in Figure 4a; mean clear width reduces with an increase of the concentration of DMH when the concentration of DMH is lower than $4 \%$, while it increases when the concentration of DMH increases beyond $4 \%$. As shown in Figure $4 \mathrm{~b}$, the mean clear width increases with the increase of the curing temperature until it reaches $140{ }^{\circ} \mathrm{C}$, but it reduces with the increase of the curing temperature beyond $140{ }^{\circ} \mathrm{C}$ (Figure $4 \mathrm{~b}$ ). As shown in Figure 4c, when the concentration of the bleaching solution is below 
$1 \%$, the mean clear width reduces with the increase of the concentration of the bleaching solution. Moreover, if the bleaching solution concentration is higher than $1 \%$, the mean clear width increases further. Figure $4 \mathrm{~d}$ shows that the mean clear width of the finished cotton fabric decreases with the increase of the time of chlorination up to $40 \mathrm{~min}$. After exceeding $40 \mathrm{~min}$, the mean clear width starts increasing.

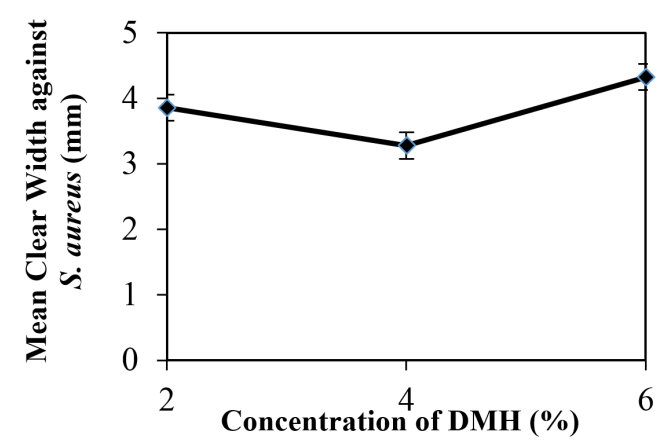

(a)

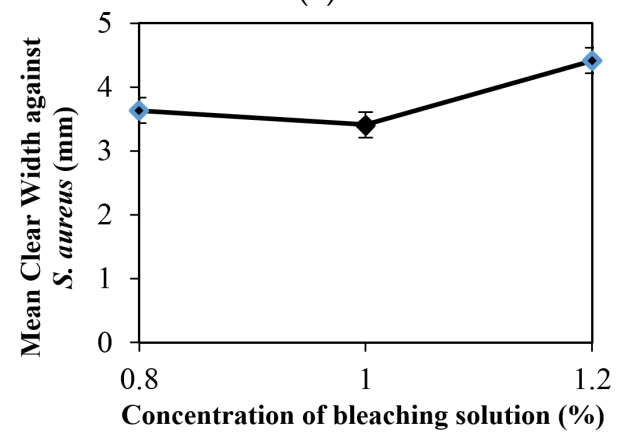

(c)

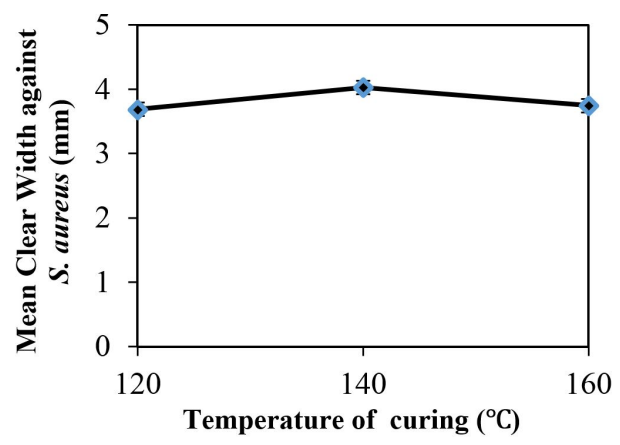

(b)

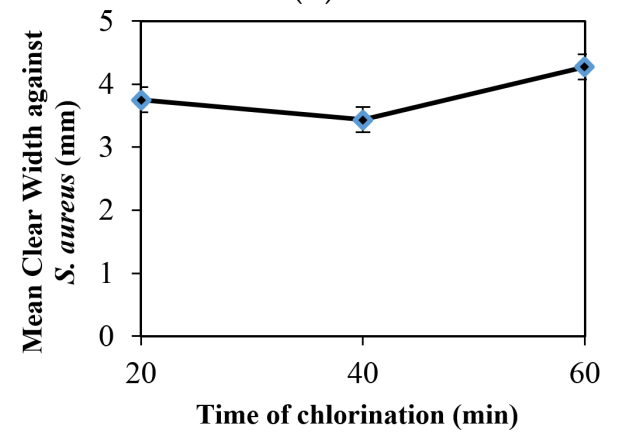

(d)

Figure 4. Effect of (a) concentration of $\mathrm{DMH}$; (b) curing temperature; (c) concentration of the bleaching solution; and (d) time of chlorination on the antibacterial property of cotton fabric coated with DMH.

\subsection{Relationship between the Antibacterial Property and the Concentration of Chlorine on Cotton Fabric}

Figure 5 shows the relationship between the antibacterial property and the concentration of chlorine on cotton fabric. It is noted that the mean clear width becomes wider with an increase of the concentration of chlorine on DMH coated cotton fabric. The relationship is logarithmic with a logarithmic equation of $y=0.933 \ln (x)+0.0155\left(R^{2}=0.91301\right)$. That is because steric hindrance of the functional groups decreases the chlorination of $\mathrm{N}$-containing groups by sodium hypochlorite $[35,36]$.

\subsection{Regenerability}

Regenerability makes antibacterial textiles environmentally-friendly, besides prolonging the service life of the fabric. Figure 6 shows the regenerability of cotton fabric with plasma treatment (symbol: CDPD) and without plasma treatment (symbol: CD). In Figure 6, the mean clear width of fabric with plasma treatment is wider than for fabric without plasma treatment whether before washing (washing time $=0$ in Figure 6), after washing (symbol: AW), or re-chlorination (symbol: $\mathrm{AW}+\mathrm{CH}$ ). According to Figure 6, the antibacterial activity of cotton fabric with plasma treatment after re-chlorination is approximately the same as that before washing. However, the antibacterial activity of fabric without plasma treatment decreases after washing and re-chlorination, compared with that before washing. It is also found that the mean clear width of fabric without plasma treatment after washing decreases significantly when compared to that with plasma treatment after washing. 


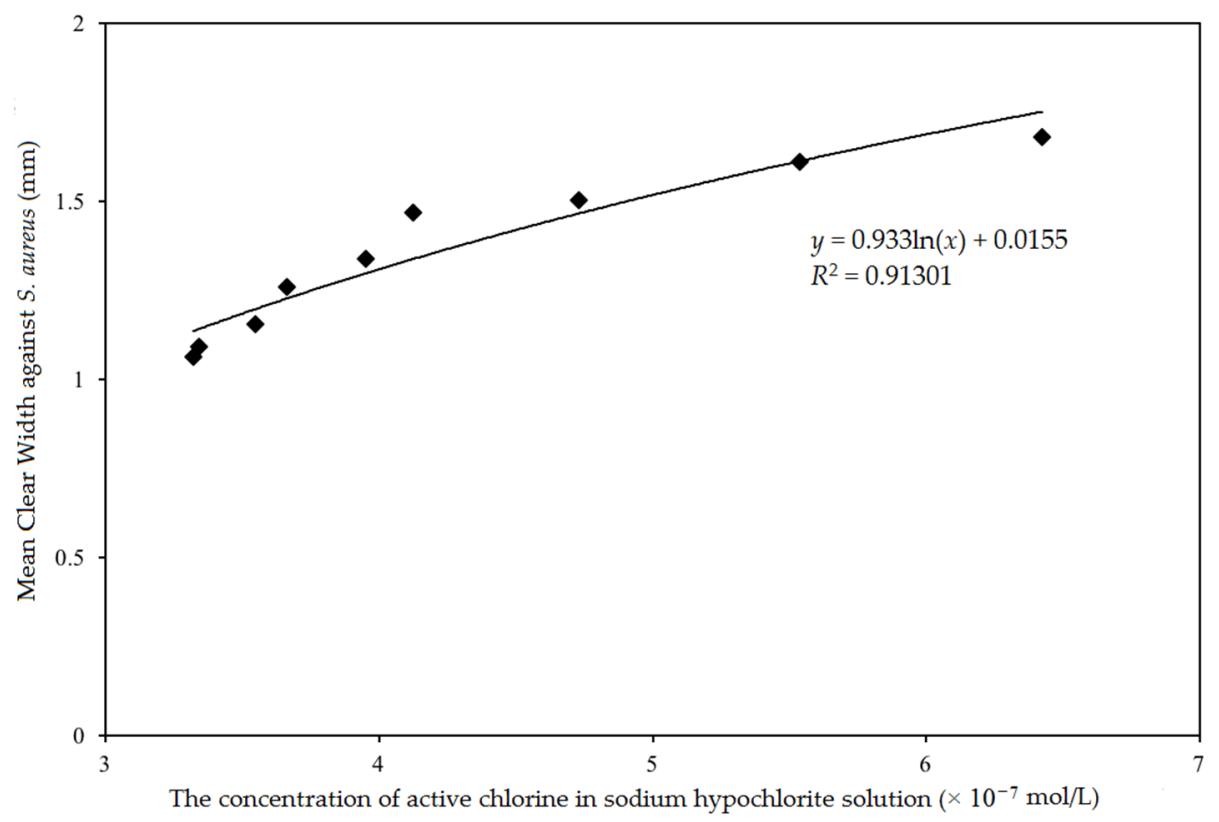

Figure 5. Relationship between the antibacterial property and the concentration of chlorine on cotton fabric.

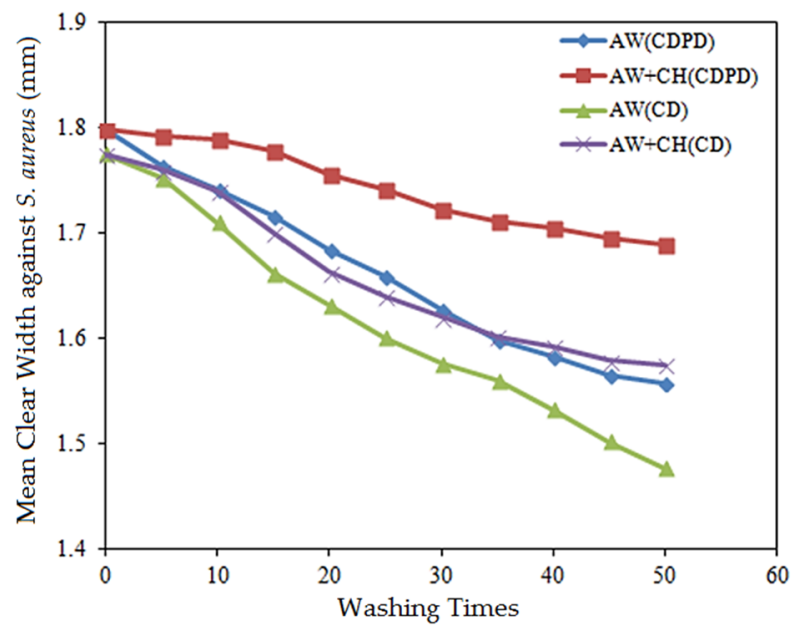

Figure 6. Antimicrobial effect of fabric finished with pad-dry-plasma-cure (CDPD) and pad-dry-cure (CD) processes before washing, after washing $(\mathrm{AW})$, and after re-chlorination $(\mathrm{AW}+\mathrm{CH})$.

\subsection{FTIR-ATR}

FTIR-ATR is used to determine the existence and the content of chemical groups on the finished substrates. In this experiment, characteristic groups of $\mathrm{DMH}$, amide II, and $\mathrm{C}=\mathrm{O}$ and other chemical groups related to $\mathrm{N}_{2}$ plasma treatment were determined. Figure 7 is the second derivative FTIR-ATR spectrum of the untreated cotton fabric (Figure 7a), cotton fabric treated with plasma (Figure 7b), cotton fabric coated with DMH with plasma treatment (Figure 7c) and cotton fabric coated with DMH without plasma treatment (Figure 7d). Compared with Figure 7a, the peaks at around $1550 \mathrm{~cm}^{-1}$ are assigned to N-H (amine II) deformation in Figure $7 \mathrm{~b}-\mathrm{d}$. The absorbance bands in the $1755 \mathrm{~cm}^{-1}$ region of Figure $7 \mathrm{~b}-\mathrm{d}$ indicate the stretching vibrations of $\mathrm{C}=\mathrm{O}[36-40]$. The absorbance peak of $\mathrm{C}=\mathrm{O}$ in Figure $7 \mathrm{~b}$ belongs to the stretching vibration of the carboxyl groups. Absorbance peaks of $\mathrm{C}=\mathrm{O}$ in Figure $7 \mathrm{~d}$ are derived from $\mathrm{DMH}$ and the absorbance peaks of $\mathrm{C}=\mathrm{O}$ in Figure $7 \mathrm{c}$ include the stretching vibration of the carboxyl groups and amides. Absorbance peaks at $3304 \mathrm{~cm}^{-1}$ represent the stretching 
vibrations of $\mathrm{N}-\mathrm{H}$ [24]. The absorbance peak of $\mathrm{C}=\mathrm{O}$ and $\mathrm{N}-\mathrm{H}$ (amine II) in Figure 7c is higher than that in Figure $7 \mathrm{~b}, \mathrm{~d}$ according to coordinates of the absorbance peaks, which means fabrics finished with the pad-dry-plasma-cure process increase the content of $\mathrm{C}=\mathrm{O}$ and $\mathrm{N}-\mathrm{H}$ (amine II) groups on the basis of the Beer-Lambert law [24]. Therefore, finishing process with plasma treatment can modify the fabric surface by carboxyl groups and amides.

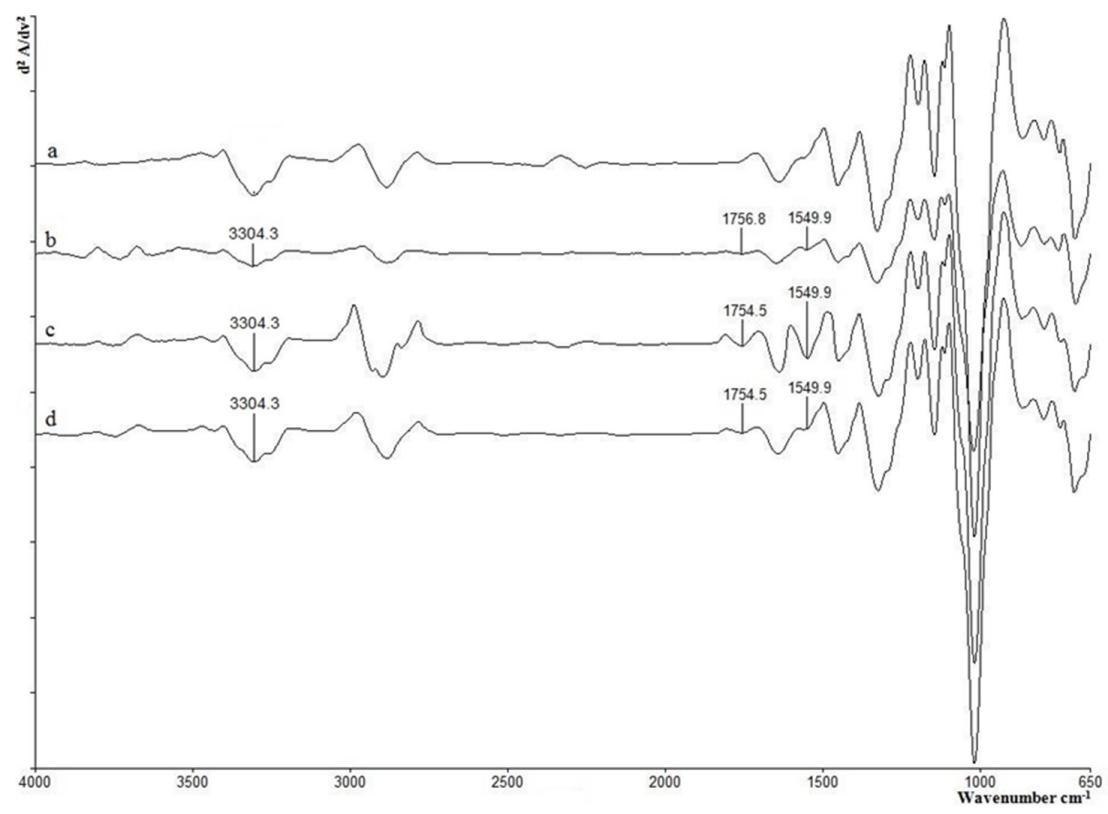

Figure 7. Second derivative FTIR spectrum of (a) untreated cotton fabric; (b) cotton fabric treated with plasma; (c) cotton fabric coated with DMH through the 'pad-dry-cure' method with plasma treatment (CDPD); and (d) cotton fabric coated with DMH through the 'pad-dry-cure' method (CD).

\subsection{SEM}

SEM was employed to observe the variations of physical characteristics on the surface of modified substrates. Figure 8 shows a SEM picture of untreated cotton fabric (Figure 8a), cotton fabric coated with DMH through the "pad-dry-cure" method (CD) (Figure 8b), and cotton fabric coated with DMH through the 'pad-dry-plasma-cure' method (CDPD) (Figure 8c). As shown in Figure 8, the surface of the cotton fibres is smooth even before coating, while the surface of cotton fibres coated with DMH is not smooth. Compared with the distribution of DMH on fabric without plasma treatment (Figure 8b), $\mathrm{DMH}$ is more evenly distributed on the surface of fibres treated with plasma (Figure 8c). This may be caused by the etching effect, that is, species generated in a plasma generator possess active energy, which collides with material surfaces to remove some line-structures on the fibre surfaces [23,41,42].
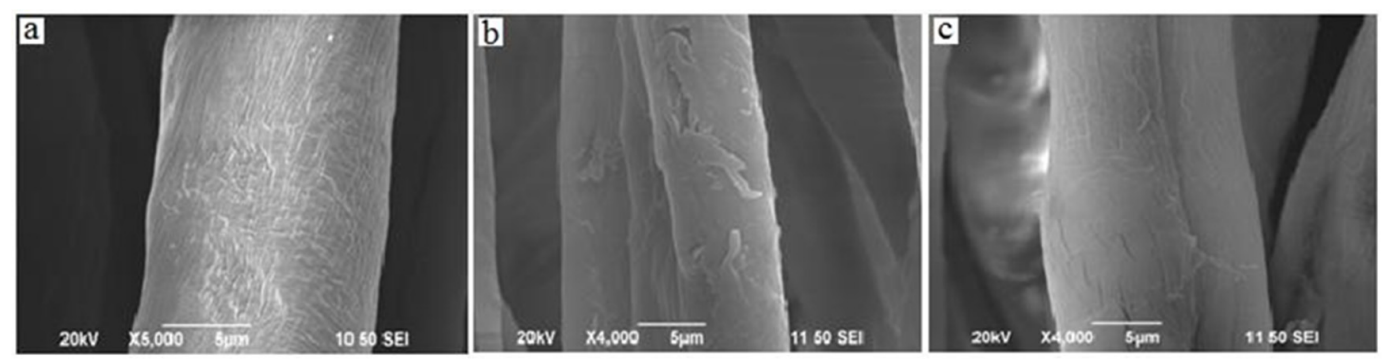

Figure 8. SEM picture of (a) untreated cotton fabric; (b) cotton fabric coated with DMH through the "pad-dry-cure" method (CD); and (c) coated with DMH through the 'pad-dry-cure' method with plasma treatment (CDPD). 


\subsection{Tearing Strength}

Tearing strength of the untreated fabric, fabric coated with DMH (CD), and fabric coated with $\mathrm{DMH}$ with plasma treatment (CDPD) is shown in Table 4. Compared with the untreated fabric, the tearing strength of the cotton fabrics decrease about $5 \%$ in the warp direction and $10 \%$ in the weft direction after coating with $\mathrm{DMH}$ with or without plasma treatment. The tearing strength of cotton fabric without plasma treatment is nearly the same as that with plasma treatment. That is to say, the etching effect of the plasma treatment has no significant influence on the tearing strength when plasma treatment is carried out after drying.

Table 4. Tearing strength of the untreated cotton fabric and cotton fabric finished with pad-dry-plasma-cure (CDPD) and pad-dry-cure (CD) processes both in the warp and weft direction.

\begin{tabular}{cccc}
\hline Sample & Untreated & CD & CDPD \\
\hline Tearing strength in warp direction $(\mathrm{N})$ & 15.42 & 14.63 & 14.60 \\
Tearing strength in weft direction $(\mathrm{N})$ & 10.4 & 9.42 & 9.60 \\
\hline
\end{tabular}

\section{Discussion}

In this study, it was found that $\mathrm{N}_{2}$ plasma treatment functionalises the cotton fabric with $\mathrm{N}$-containing groups and $\mathrm{C}=\mathrm{O}$ groups, according to the FTIR study [43]. The formation of carboxyl groups on fabric after plasma treatment is caused by the oxidation of hydroxyl groups by particles in $\mathrm{N}_{2}$ plasma, and they can react with amide groups in a hydantoin ring [44]. The higher absorbance peak of $\mathrm{C}=\mathrm{O}$ in Figure 7c means the content of $\mathrm{C}=\mathrm{O}$ in Figure 7c is 1.7 times higher than that in Figure $7 \mathrm{~b}$ and 1 time in Figure $7 \mathrm{~d}$. According to the Beer-Lambert law, $A=\log _{10}\left(I_{0} / I\right)=\mathrm{abc}$ (where $A$ is the absorbance of functional groups; $I_{0}$ is the intensity of source radiation; $\mathrm{I}$ is the intensity of transmitted radiation; $a$ is the absorpitivity co-efficient, $b$ is the thickness of the path length; and $c$ is the concentration of the absorber), the height of a second-derivative peak in the FTIR spectrum is proportional to the square of the original peak height with an opposite sign [44].

In addition, plasma treatment imparts an etching effect on the material surface leading to the formation of grooves and cracks [45]. In this study, the fabric is first covered by DMH in a pad-dry-plasma-cure process, and when the plasma particles reach the surface of the fabric, they initially interact with DMH. Thus, distribution and coating of DMH onto cotton fabrics is improved by plasma treatment. Meanwhile, the cracks and DMH on the fabric increase the surface friction and roughness, which restricts the sliding action of the yarn during tearing and leads to lower tearing strength $[23,46,47]$. However, the DMH attached to the fabric decreases the etching effect of plasma treatment which prevents the tearing strength of the fabric from declining. Therefore, $\mathrm{N}_{2}$ plasma treatment introduces $\mathrm{N}$-containing groups and improves the content of $\mathrm{DMH}$ on cotton fabric, which increases the content of chlorine and enhances the antibacterial effect as well as its regenerability [24]. The plasma treatment applied after drying is a feasible way for improved functional finishing of cotton fabric.

It was also discovered that the process variables affect the antibacterial properties of cotton fabric finished with DMH. Firstly, the higher concentration of the DMH solution results in the aggregation of molecules of $\mathrm{DMH}$, which affects the distribution and adhesion of $\mathrm{DMH}$ on fabric, resulting in a decrease of the mean clear width with an increase in the concentration of DMH. However, when the concentration of DMH is high enough, the aggregated DMH can cover a larger surface area and more DMH can be coated on the fabric. This explains why the mean clear width increases with the concentration of DMH until the DMH concentration reaches $6 \%[25,26]$. Secondly, the melting point of $\mathrm{DMH}$ is around $175^{\circ} \mathrm{C}$ and thus with a high curing temperature, the $\mathrm{DMH}$ can get detached from the fabric surface leading to poor fixation of DMH on fabric $[25,26]$. So DMH may be dissolved in water easily during the subsequent finishing process. Therefore, the DMH content on the fabric 
and chlorine decrease with the increase of the curing temperature, and the resultant antibacterial properties decrease. Generally speaking, a higher concentration of the bleaching solution provides more chlorine to interact with the DMH in the cotton fabric. Therefore, the chlorine concentration of fabric increases with an increase in the concentration of the bleaching solution [25], but this assumption could not be verified by the outcome as depicted in Figure 4c. Generally speaking, chlorine in sodium hypochlorite has a strong oxidising ability which is considered able to damage functional moieties, such as potential aldehyde groups on the cotton fabric [26]. This damage may contribute to the occurrence of decreased antibacterial efficacy of the treated fabrics when fabrics are chlorinated with higher concentration of sodium hypochlorite solution. In this study, the $\mathrm{N}$-containing groups came from two sources: $\mathrm{DMH}$ and $\mathrm{N}_{2}$ plasma [41]. $\mathrm{N}$-containing groups in $\mathrm{DMH}$ are chlorinated easily due to the effect of steric hindrance of functional groups in cellulose molecules [26]. When the concentration of sodium hypochlorite is lower than $1 \%$, chlorine is consumed by the $\mathrm{N}$-containing groups in $\mathrm{DMH}$ and functional groups on the cotton fabric. With the increase of the bleaching solution concentration, redundant chlorine has the chance to react with $\mathrm{N}$-containing groups introduced by $\mathrm{N}_{2}$ plasma [25]. This explains why the mean clear width is nearly stable with an increase in the bleaching solution concentration when the bleaching solution concentration is lower than $1 \%$, and why it increases with the increase in concentration of the bleaching solution after the concentration exceeds $1 \%$. The last factor is the time of chlorination. Because there are two sources of $\mathrm{N}$-containing groups, at the beginning of chlorination, $\mathrm{N}$-containing groups in $\mathrm{DMH}$ are chlorinated by sodium hypochlorite due to the steric hindrance of vicinal chemical groups of $\mathrm{N}$-containing groups introduced by the nitrogen plasma on cotton fabrics $[35,36]$. However, the $\mathrm{N}-\mathrm{Cl}$ structure in $\mathrm{DMH}$ is not stable. $\mathrm{N}-\mathrm{Cl}$ bonds are hydrolysed (reverse reaction, Figure 1) with extension of the time of chlorination [48]. Functional groups in DMH are potentially destroyed by the strong oxidising ability of sodium hypochlorite. Meanwhile, nitrogen plasma introduces $\mathrm{N}$-containing groups which are transferred into the $\mathrm{N}$-halamine structure with the extension of chlorination time [24-27]. Therefore, the mean clear width of cotton fabric increases after the initial decrease.

It is demonstrated that the antibacterial activity is proportional to the concentration of chlorine on the finished cotton fabric. Therefore, the effective method to improve the antibacterial property of cotton fabric is to increase the amount of chlorine on the cotton fabric.

\section{Conclusions}

The pad-dry-plasma-cure process for coating DMH on cotton fabric followed by chlorination with sodium hypochlorite inhibits the bacteria, S. aureus, effectively. The optimum treatment conditions of the antibacterial finishing process as identified in this research are (i) concentration of $\mathrm{DMH}=6 \%$; (ii) curing temperature $=140{ }^{\circ} \mathrm{C}$; (iii) concentration of bleaching solution $=1.2 \%$; and (iv) time of chlorination $=60 \mathrm{~min}$. In the future, the finishing process can be optimized further by variance analysis through orthogonal experiments considered with interaction and error terms.

The antibacterial property of cotton fabric coated with DMH with the aid of plasma treatment followed by chlorination is regenerable, durable, and stable. The appearance, distribution, and content of DMH on cotton fabrics are enhanced by plasma treatment. Nitrogen plasma also introduces nitrogen-containing groups onto the surface of cotton fabrics, which enhances the antibacterial activity directly. Meanwhile, plasma treatment has no significant effect on the tearing strength of cotton fabric coated with DMH through the pad-dry-plasma-cure process.

With the regenerable antibacterial property, the cotton fabric can be potentially used for healthcare products in which a bleaching agent containing chlorine may be used as a sterilisation agent during the washing process. However, in future work, it is recommended to use X-ray photoelectron spectroscopy (XPS) to detect the variation of the chemical elements quantitatively. This characterization technique provides a more precise result of the variation of chemical elements on the surface of materials. In order to ensure the safety of finished fabrics that come in contact with humans, cytotoxicity testing should be performed, on account of the chlorine involved in the finishing process. 
Acknowledgments: This work is financially supported by the Research Grants Council of The Hong Kong Special Administrative Region, China (Project No. PolyU 5173/11E) and The Hong Kong Polytechnic University.

Author Contributions: Chi-wai Kan proposed the project. Chang-E. Zhou wrote the main manuscript text. Chang-E. Zhou and Chi-wai Kan performed the experiments and analyzed the results. Jukka Pekka Matinlinna and James Kit-hon Tsoi advised the technical content and revised the language of the manuscript. All authors reviewed the manuscript.

Conflicts of Interest: The authors declare no conflict of interest.

\section{References}

1. Thanh, N.V.K.; Phong, N.T.P. Investigation of antibacterial activity of cotton fabric incorporating nano silver colloid. J. Phys. 2009, 187, 1-7. [CrossRef]

2. Kenawy, E.; Abdel-Fattah, Y.R. Antimicrobial properties of modified and electrospun poly (vinyl phenol). Macromol. Biosci. 2002, 2, 261-266. [CrossRef]

3. Lala, N.L.; Ramaseshan, R.; Bojun, L.; Sundarrajan, S.; Barhate, R.S.; Ying-Jun, L.; Ramakrishna, S. Fabrication of nanofibers with antimicrobial functionality used as filters: Protection against bacterial contaminants. Biotechnol. Bioeng. 2007, 97, 1357-1365. [CrossRef] [PubMed]

4. Gouda, M.; Ibrahim, N. New approach for improving antibacterial functions of cotton fabric. J. Ind. Text. 2008, 37, 327-339. [CrossRef]

5. Lim, S.; Hudson, S.M. Application of a fiber-reactive chitosan derivative to cotton fabric as an antimicrobial textile finish. Carbohydr. Polym. 2004, 56, 227-234. [CrossRef]

6. Abidi, N.; Hequet, E.; Cabrales, L. Changes in sugar composition and cellulose content during the secondary cell wall biogenesis in cotton fibers. Cellulose 2010, 17, 153-160. [CrossRef]

7. Chen, S.; Chen, S.; Jiang, S.; Xiong, M.; Luo, J.; Tang, J.; Ge, Z. Environmentally friendly antibacterial cotton textiles finished with siloxane sulfopropylbetaine. ACS Appl. Mater. Interfaces 2011, 3, 1154-1162. [CrossRef] [PubMed]

8. Sun, G.; Xu, X.; Bickett, J.R.; Williams, J.F. Durable and regenerable antibacterial finishing of fabrics with a new hydantoin derivative. Ind. Eng. Chem. Res. 2001, 40, 1016-1021. [CrossRef]

9. Liu, S.; Sun, G. Durable and regenerable biocidal polymers: Acyclic N-halamine cotton cellulose. Ind. Eng. Chem. Res. 2006, 45, 6477-6482. [CrossRef]

10. Ye, W.; Xin, J.H.; Li, P.; Lee, K.D.; Kwong, T. Durable antibacterial finish on cotton fabric by using chitosan-based polymeric core-shell particles. J. Appl. Polym. Sci. 2006, 102, 1787-1793. [CrossRef]

11. Son, Y.; Kim, B.; Ravikumar, K.; Lee, S. Imparting durable antimicrobial properties to cotton fabrics using quaternary ammonium salts through 4-aminobenzenesulfonic acid-chloro-triazine adduct. Eur. Polym. J. 2006, 42, 3059-3067. [CrossRef]

12. Hebeish, A.; El-Naggar, M.E.; Fouda, M.M.G.; Ramadan, MA.; Al-Deyab, S.S.; El-Rafie, M.H. Highly effective antibacterial textiles containing green synthesized silver nanoparticles. Carbohydr. Polym. 2011, 86, 936-940. [CrossRef]

13. Lee, H.; Yeo, S.; Jeong, S. Antibacterial effect of nanosized silver colloidal solution on textile fabrics. J. Mater. Sci. 2003, 38, 2199-2204. [CrossRef]

14. Perelshtein, I.; Applerot, G.; Perkas, N.; Wehrschuetz-Sigl, E.; Hasmann, A.; Guebitz, G.; Gedanken, A. CuO-cotton nanocomposite: Formation, morphology, and antibacterial activity. Surf. Coat. Technol. 2009, 204, 54-57. [CrossRef]

15. Jia, B.; Mei, Y.; Cheng, L.; Zhou, J.; Zhang, L. Preparation of copper nanoparticles coated cellulose films with antibacterial properties through one-step reduction. ACS Appl. Mater. Interfaces 2012, 4, $2897-2902$. [CrossRef] [PubMed]

16. Leroux, F.; Perwuelz, A.; Campagne, C.; Behary, N. Atmospheric air-plasma treatments of polyester textile structures. J. Adhes. Sci. Technol. 2006, 20, 939-957. [CrossRef]

17. Zhou, C.E.; Kan, C.W. Plasma-assisted regenerable chitosan antimicrobial finishing for cotton. Cellulose 2014, 21, 2951-2962. [CrossRef]

18. Hegemann, D. Plasma polymerization and its applications in textiles. Indian J. Fibre Text. Res. 2006, 31, 99-115. 
19. Bertaux, E.; Le Marec, E.; Crespy, D.; Rossi, R.; Hegemann, D. Effects of siloxane plasma coating on the frictional properties of polyester and polyamide fabrics. Surf. Coat. Technol. 2009, 204, 165-171. [CrossRef]

20. Abidi, N.; Hequet, E. Cotton fabric graft copolymerization using microwave plasma. I. Universal attenuated total reflectance-FTIR study. J. Appl. Polym. Sci. 2004, 93, 145-154. [CrossRef]

21. Virk, R.K.; Ramaswamy, G.N.; Bourham, M.; Bures, B.L. Plasma and antimicrobial treatment of nonwoven fabrics for surgical gowns. Text. Res. J. 2004, 74, 1073-1079. [CrossRef]

22. Morent, R.; De Geyter, N.; Verschuren, J.; De Clerck, K.; Kiekens, P.; Leys, C. Non-thermal plasma treatment of textiles. Surf. Coat. Technol. 2008, 202, 3427-3449. [CrossRef]

23. Zhou, C.E.; Kan, C.W.; Yuen, C.W.M.; Lo, K.Y.C.; Ho, C.P.; Lau, K.W.R. Regenerable antimicrobial finishing of cotton with nitrogen plasma treatment. BioResources 2016, 11, 1554-1570. [CrossRef]

24. Zhou, C.E.; Kan, C.W. Plasma-enhanced regenerable 5,5-dimethylhydantoin (DMH) antibacterial finishing for cotton fabric. Appl. Surf. Sci. 2015, 328, 410-417. [CrossRef]

25. Zhou, C.E.; Kan, C.W. Optimizing rechargeable antimicrobial performance of cotton fabric coated with 5,5-dimethylhydantoin (DMH). Cellulose 2015, 22, 879-886. [CrossRef]

26. Zhou, C.E.; Kan, C.W.; Yuen, C.W.M. Orthogonal analysis for rechargeable antimicrobial finishing of plasma pretreated cotton. Cellulose 2015, 22, 3465-3475. [CrossRef]

27. Zhou, C.E.; Kan, C.W.; Yuen, C.W.M.; Matinlinna, J.P.; Tsoi, J.K.H.; Zhang, Q. Plasma treatment applied in the pad-dry-cure process for making rechargeable antimicrobial cotton fabric that inhibits S. Aureus. Text. Res. J. 2015, 86, 2202-2215. [CrossRef]

28. Kan, C.W. Evaluating antistatic performance of plasma-treated polyester. Fibers Polym. 2007, 8, 629-634. [CrossRef]

29. Kan, C.W.; Yuen, C.W.M.; Wong, W.Y. Optimizing color fading effect of cotton denim fabric by enzyme treatment. J. Appl. Polym. Sci. 2011, 120, 3596-3603. [CrossRef]

30. Sathianarayanan, M.; Bhat, N.; Kokate, S.; Walunj, V. Antibacterial finish for cotton fabric from herbal products. Indian J. Fibre Text. Res. 2010, 35, 50-58.

31. Scholz, J.; Nocke, G.; Hollstein, F.; Weissbach, A. Investigations on fabrics coated with precious metals using the magnetron sputter technique with regard to their anti-microbial properties. Surf. Coat. Technol. 2005, 192, 252-256. [CrossRef]

32. Mohammadkhodaei, Z.; Mokhtari, J.; Nouri, M. Novel anti-bacterial acid dyes derived from naphthalimide: Synthesis, characterisation and evaluation of their technical properties on nylon 6. Coloration Technol. 2010, 126, 81-85. [CrossRef]

33. Daoud, W.A.; Xin, J.H.; Tao, X.M. Superhydrophobic silica nanocomposite coating by a low-temperature process. J. Am. Ceram. Soc. 2004, 87, 1782-1784. [CrossRef]

34. Chuanwen, C.; Feng, S.; Yuguo, L.; Shuyun, W. Orthogonal analysis for perovskite structure microwave dielectric ceramic thin films fabricated by the RF magnetron-sputtering method. J. Mater. Sci. 2010, 21, 349-354. [CrossRef]

35. Kocer, H.B.; Akdag, A.; Ren, X.; Broughton, R.M.; Worley, S.D.; Huang, T.S. Effect of alkyl derivatization on several properties of N-halamine antimicrobial siloxane coatings. Ind. Eng. Chem. Res. 2008, 47, 7558-7563. [CrossRef]

36. Qian, L.; Sun, G. Durable and regenerable antimicrobial textiles: Synthesis and applications of 3-methylol-2,2,5,5-tetramethyl-imidazolidin-4-one (MTMIO). J. Appl. Polym. Sci. 2003, 89, 2418-2425. [CrossRef]

37. Wang, L.; Xie, J.; Gu, L.; Sun, G. Preparation of antimicrobial polyacrylonitrile fibers: Blending with polyacrylonitrile-co-3-allyl-5,5-dimethylhydantoin. Polym. Bull. 2006, 56, 247-256. [CrossRef]

38. El-Newehy, M.H.; Al-Deyab, S.S.; Kenawy, E.; Abdel-Megeed, A. Nanospider technology for the production of nylon-6 nanofibers for biomedical applications. J. Nanomater. 2011, 2011, 626589. [CrossRef]

39. Sun, X.; Cao, Z.; Porteous, N.; Sun, Y. An N-halamine-based rechargeable antimicrobial and biofilm controlling polyurethane. Acta Biomater. 2012, 8, 1498-1506. [CrossRef] [PubMed]

40. Kocer, H.B.; Worley, S.; Broughton, R.; Huang, T. A novel N-halamine acrylamide monomer and its copolymers for antimicrobial coatings. React. Funct. Polym. 2011, 71, 561-568. [CrossRef]

41. Yoon, N.S.; Lim, Y.J.; Tahara, M.; Takagishi, T. Mechanical and dyeing properties of wool and cotton fabrics treated with low temperature plasma and enzymes. Text. Res. J. 1996, 66, 329-336. [CrossRef] 
42. Wong, K.K.; Tao, X.M.; Yuen, C.W.M.; Yeung, K.W. Low temperature plasma treatment of linen. Text. Res. J. 1999, 69, 846-855. [CrossRef]

43. Silva, S.S.; Luna, S.M.; Gomes, M.E.; Benesch, J.; Pashkuleva, I.; Mano, J.F.; Reis, R.L. Plasma surface modification of chitosan membranes: Characterization and preliminary cell response studies. Macromol. Biosci. 2008, 8, 568-576. [CrossRef] [PubMed]

44. Max, J.J.; Chapados, C. Infrared spectroscopy of aqueous carboxylic acids: Comparison between different acids and their salts. J. Phys. Chem. A 2004, 108, 3324-3337. [CrossRef]

45. Karahan, H.; Özdoğan, E. Improvements of surface functionality of cotton fibers by atmospheric plasma treatment. Fibers Polym. 2008, 9, 21-26. [CrossRef]

46. Cheng, S.Y.; Yuen, C.W.M.; Kan, C.W.; Cheuk, K.K.L.; Daoud, W.A.; Lam, P.L.; Tsoi, W.Y.I. Influence of atmospheric pressure plasma treatment on various fibrous materials: Performance properties and surface adhesion analysis. Vacuum 2010, 84, 1466-1470. [CrossRef]

47. Kan, C.W.; Chan, K.; Yuen, C.W.M. A study of the oxygen plasma treatment on the serviceability of a wool fabric. Fibers Polym. 2004, 5, 213-218. [CrossRef]

48. Sun, G.; Worley, S.D. Chemistry of durable and regenerable biocidal textiles. J. Chem. Educ. 2005, 82, 60-64. [CrossRef]

(C) 2017 by the authors; licensee MDPI, Basel, Switzerland. This article is an open access article distributed under the terms and conditions of the Creative Commons Attribution (CC-BY) license (http://creativecommons.org/licenses/by/4.0/). 